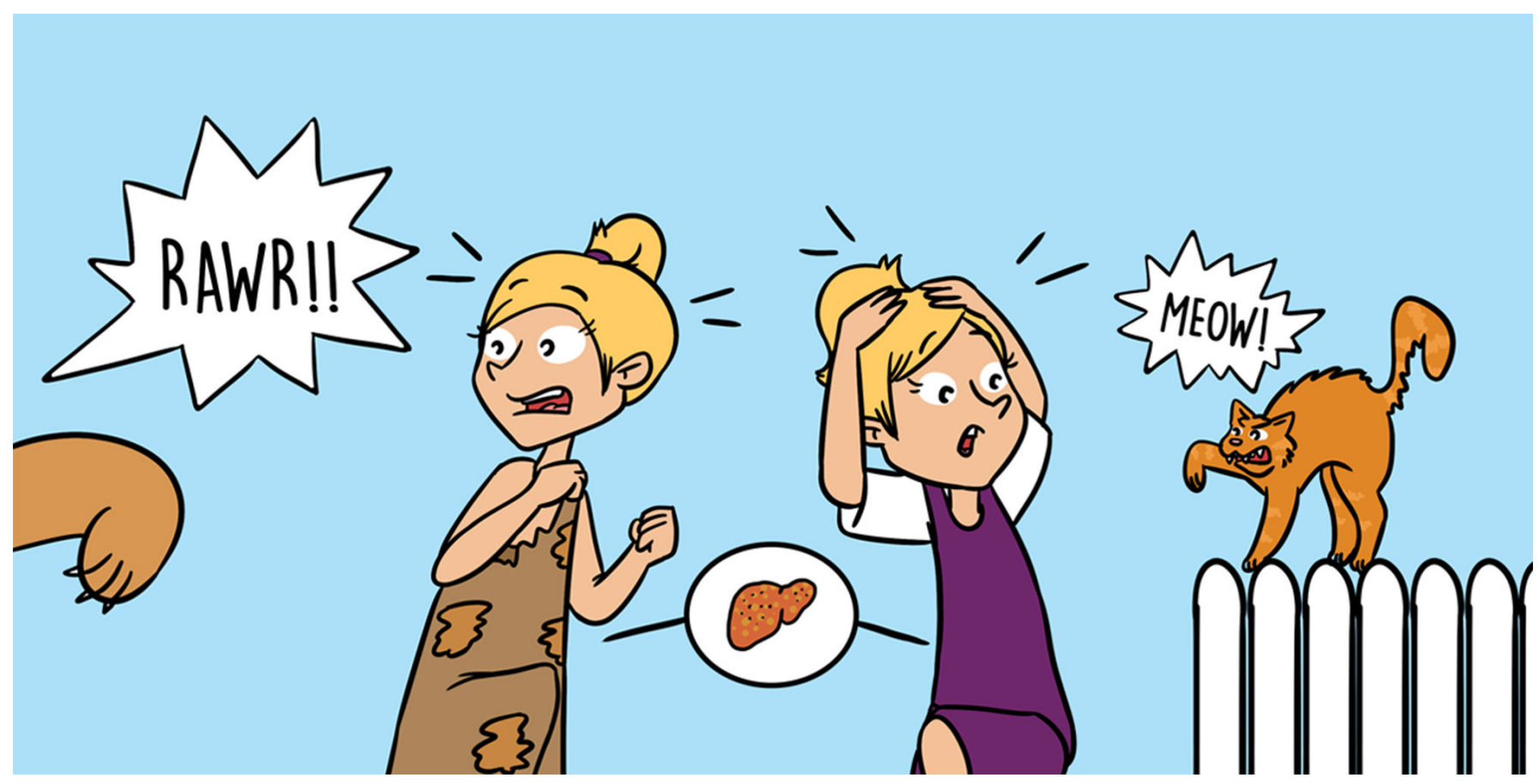

\title{
FEAR, FAT, AND GENES: NEW ANSWERS TO OLD QUESTIONS
}

\section{Hermona Soreq*}

The Hebrew University of Jerusalem, Jerusalem, Israel

\section{YOUNG REVIEWERS:}

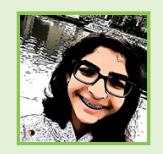

ANISHA

AGE: 14

ETGAR CLASS,

OHRTORAH

STONE SEMINARY

AGES: $13-14$
Our brains instruct our bodies how to react to external stimulation. In people exposed to traumatic experiences the brain automatically sends messages that can limit certain gene activities. Humans have retained the automatic reflex of ancient people to traumatic experiences. Ancient men and women needed to save energy to ensure their survival under traumatic situations, and accumulating fat in their liver might have provided them with an increased chance of survival. These days, however, fatty liver disease is dangerous and, unfortunately, very common. How does trauma lead to liver fattening? We discovered the genetic mechanism that leads to accumulation of fat in the liver of mice under trauma, and a potential treatment to reduce this fat. In this research we demonstrated how research combining neuroscience and genetics can offer new solutions to evolutionarily old questions. 


\section{REACTION TO TRAUMA IN EVOLUTION}

All living creatures on earth are tuned to react to traumatic experiences. For example, a mouse that sees a cat runs as fast as it can to avoid being caught. Also, this mouse forgets to eat, because that is less important than escaping the risk of death, and its white blood cells are on the alert, so that if it is injured, and then exposed to bacteria, these white blood cells will protect the injured mouse from bacterial infection. When the mouse encounters a second cat, this mouse will already know how to react. Exposure to traumatic experiences can therefore prepare both the brain and the body of traumatized creatures to survive this trauma and may also prepare them to react better if another traumatic situation emerges [1].

Humans, like all creatures, react to trauma. The reaction starts with fear and leads to many changes in how our body functions (for example, the rate of our heart beats increases under fear [2]). Furthermore, we may react to trauma better than any other creature, since the human brain's weight, when calculated as part of their body weight, is considerably larger than that of all other creatures. Therefore, both our perception of traumatic experiences and the human response to such events may be more elaborate and perhaps more effective than those of the mouse running for its life.

If we look back in evolution, we find that creatures with such large brains did not exist until 2-3 million years ago, meaning that this change in the brain's weight and capacities happened very rapidly in evolutionary terms. Indeed, scientists have wondered how could this jump in brain size and capabilities have happened so "quickly" and what it might have meant for trauma reactions. Most scientists believe that genes, the functional building blocks of our DNA, directed this change.

Let us start our journey with a simple question: are modern humans exposed to the same type of traumatic events as the ancient wild man in the savanna many thousands of years ago? The answer is probably no; ancient men or women were traumatized by a lion running after them, and had to react rapidly in order not to be eaten by that lion. Also, those wild humans sometimes needed to hide in caves to avoid lions, with nothing to eat there. So, those people who managed to keep and preserve every bit of energy they got in their food had better

\section{FATTY LIVER}

A common disease of fat accumulation in the liver that can lead to cancer and death. prospects to survive such a trauma. For them having a fatty liver was an advantage, but for us it is a threat [3]. In comparison, nowadays we get traumatized when we watch a scary movie on television, and the danger is far less immediate and threatening, and yet we seek food as 
EVOLUTIONARY

\section{CHANGES}

Mutations, deletions, and additions to DNA that have accumulated over hundreds of thousands of years and have influenced the organisms that carry them.

\section{MICRORNA}

Short RNA sequences which block protein production by binding to their complementary RNA sequences. if to prepare for hiding in that cave from ancient times, because our body and brain and our DNA are built similarly to those of those wild humans in the savanna [4].

That our biology is very much like that of the wild humans in the savanna, indicates that we tend to react to such stresses like those humans-or like the mouse running away from a cat-because our brain and our genes tell us to do that. Ancient traumas and modern ones cause the body to react in the same way. Namely, when we are traumatized, our running instincts are boosted, our immune system (the network of cells, tissues, and organs that work together to defend the body against attacks by "foreign" invaders) lights up, and our appetite is modifiedsome people stop eating altogether when traumatized, saving all of their energy to the reaction to trauma; others will eat non-stop, so that they are better fit for hiding in a cave with no food. In both cases, it is our brain and our genes that tell the body to change its activities due to the trauma.

Darwin taught us that only those creatures who are most suited have survived evolutionary changes, and superior trauma reactions should play an important part in the survival of species [5]. We therefore assume that human beings developed better skills to react to trauma, and that those skills helped us to survive as a species.

\section{MICRORNAS AND REACTION TO TRAUMA}

Each cell in our body includes the full copy of the DNA. Only a small part of the DNA in these cells contains genes, that carry the information to make proteins. Other genes hold instructions to produce different kind of molecules called RNA. There are large and small RNA molecules. In our laboratory, we study the newly discovered family of the tiny microRNA genes, and test if they may be responsible for the response of humans to trauma.

The newly discovered family of "microRNAs," many of which have emerged during primates' (apes, gorillas, etc.) evolution are excellent candidates to be involved in response to trauma. Scientists have known about these miniature genes, 100 times smaller than "regular" genes, for $<30$ years. Nevertheless, those researchers who discovered them won the Nobel prize in 2006 and made a major impact on our understanding of how the brain functions and how it sends messages to the body. We suspect that these microRNAs are very important to our trauma reactions [6]. So, to understand what happens under trauma, let us discuss the way microRNAs function. 


\section{Figure 1}

MicroRNAs wrap around their target genes and block their functioning. Shown is a computer-designed molecular model of a microRNA (orange) wrapped around its target gene (green), which blocks it and prevents protein production by that gene in the stressed brain neurons (gray figures in the background).

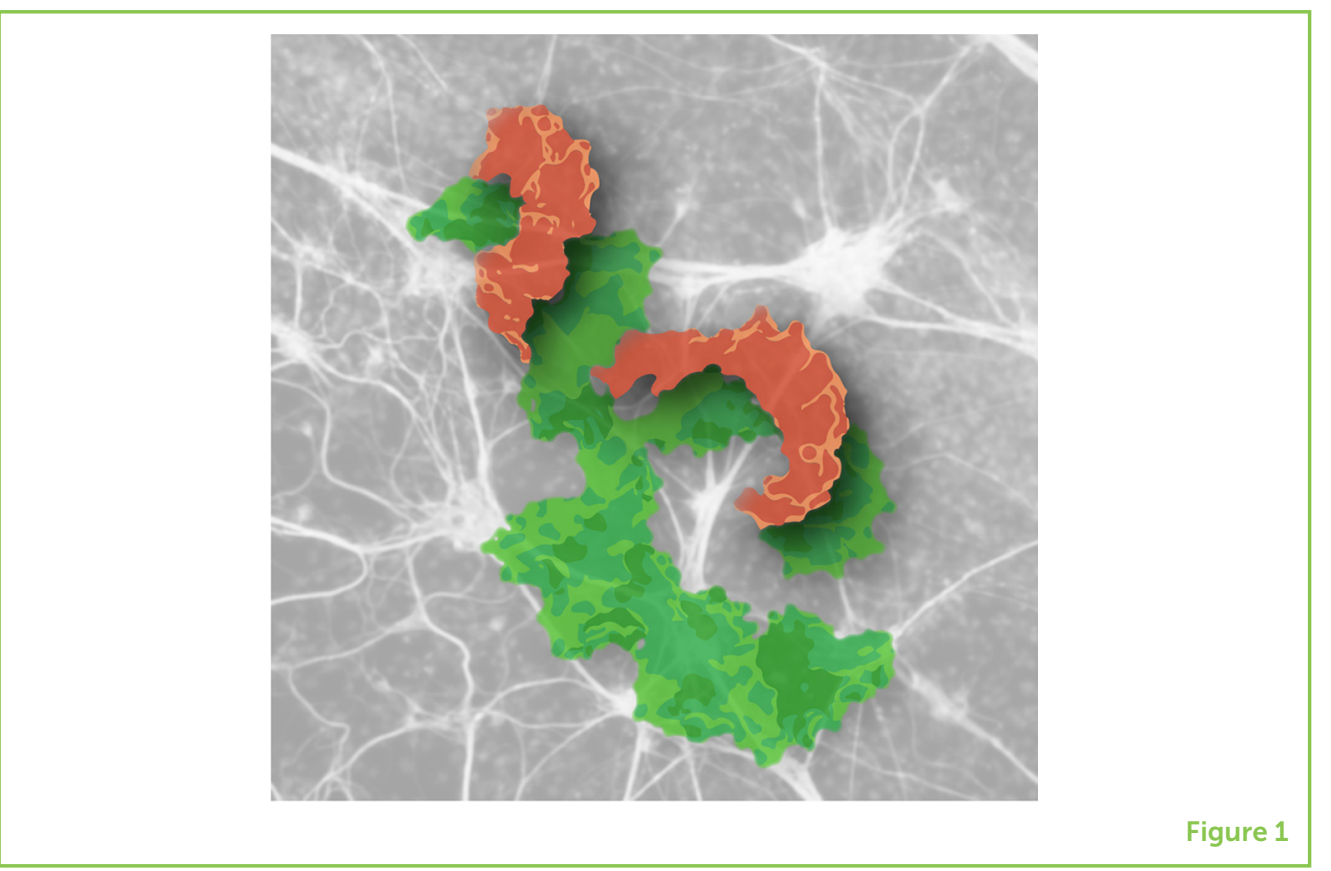

MicroRNAs wrap around other genes that include "mirror" sequences to them and by that prevent them from producing proteins. As the microRNA is much smaller than the gene, the "mirror" sequence is just a small part of the gene. MicroRNAs may do this with any gene that shares such "mirror" sequences, which often happens to genes that are involved in a specific function; for example, many of the traumaresponding genes would share such sequences and will therefore all be blocked by the same microRNAs. In other words, microRNAs operate a little bit like electricity dimmers that turn down the light in an entire room. Figure 1 shows how microRNA wraps around another gene that includes a "mirror" sequence.

There are over 2,500 microRNA genes, one third of which emerged during the evolution of large primates (so that humans, but not mice would have them). These "young" microRNAs might be important for our reactions to trauma, since many of the microRNAs control brain functioning, and get activated under traumatic situations. However, microRNAs also control our energy balance, governing the chemical processes that occur within a living organism in order to maintain life (metabolic processes) by "packing" energy in fat molecules. Importantly, many of the trauma-responding microRNAs also get activated when metabolic processes involved in energy preservation are turned on, suggesting that our brain regulates trauma and metabolism processes together [7]. Figure 2 shows fat droplets where energy can be saved [8]. 


\section{Figure 2}

Fat droplets are great energy reservoirs. In the liver, energy is saved as tiny fat droplets shown as orange balls that may accumulate there for a long time and be degraded when the energy is needed. That was useful for the wild man in the desert but may cause disease in modern humans.

\section{GENETIC}

ENGINEERING

A research field that specializes in introducing controlled changes to the DNA of cells in culture and animals in the lab.

\section{SYNTHETIC DNA}

DNA strands made by machine according to a given sequence. Synthetic DNA can be used as drugs.

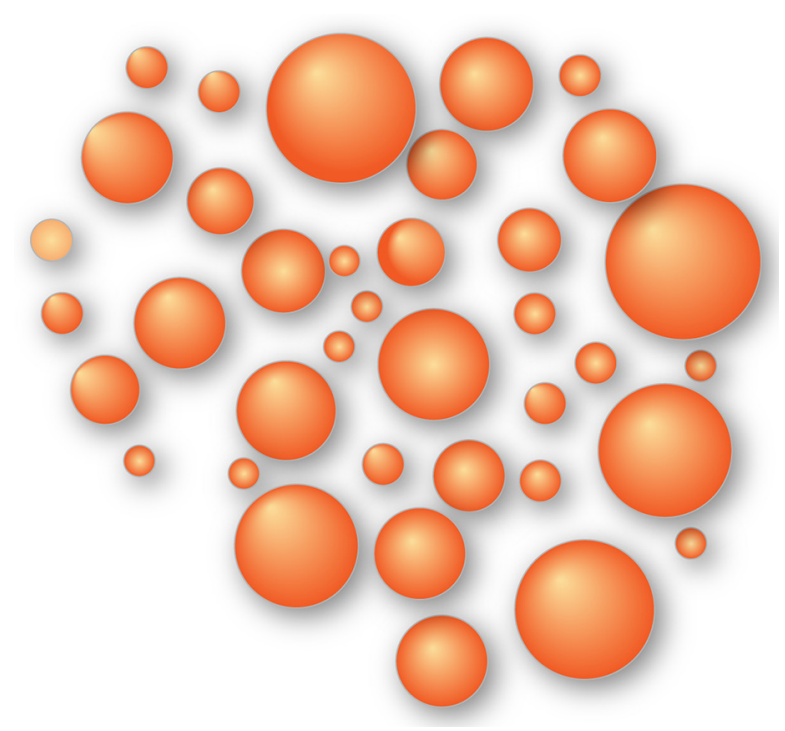

Figure 2

\section{OUR RESEARCH}

How can we test if this theory, that the brain connects evolution, trauma, and metabolism together, is true? What one needs to do is to focus on a single example. We selected one microRNA named microRNA-132 that is involved both in trauma responses and in energy preservation. Using genetic engineering methods, we injected mouse eggs with this microRNA-132 gene. These eggs were fertilized outside of the body and implanted in the mouse womb, which led to the birth of "engineered" mice, that produce a lot of microRNA-132 in their body tissues (but not in their brains). Importantly, these mice became very fat (even though they were eating regular food), indicating that extra microRNA-132 may cause fat accumulation in body tissues by wrapping around certain genes.

To really prove if this is the case, we fed regular mice with a fat-rich diet, which led to fat mice with an accumulation of microRNA-132 in their liver. We then injected these mice with a synthetic DNA, that binds to the microRNA-132 and obstructs its attempt to wrap around genes (called anti-microRNA-132), thus, making it less effective. Remarkably, this treatment emptied their liver from fat within 1 week, turning fatproduction to fat-destruction [9].

In our research we investigated mice, but our real question is: can people with genetic fatty liver disease benefit from our treatment: antimicroRNA-132? We treated mice with a genetic fat digestion disease with our anti-microRNA-132, and found that it successfully reduced their liver fat. To sum up, we started this journey with a research question 
on the evolution of trauma reactions, and developed a new molecule that may 1 day become a novel treatment for fatty liver disease.

\section{REFERENCES}

1. Zimmerman, G., Shaltiel, G., Barbash, S., Cohen, J., Gasho, C. J., ShenharTsarfaty, S., et al. 2012. Post-traumatic anxiety associates with failure of the innate immune receptor TLR9 to evade the pro-inflammatory NFKB pathway. Transl. Psychiatry 2:e78. doi: 10.1038/tp.2012.4

2. Shenhar-Tsarfaty, S., Yayon, N., Waiskopf, N., Shapira, I., Toker, S., Zaltser, D., et al. 2015. Fear and C-reactive protein cosynergize annual pulse increases in healthy adults. Proc. Natl. Acad. Sci. U.S.A. 112:E467-71. doi: 10.1073/pnas.1418264112

3. Rinella, M. E. 2015. Nonalcoholic fatty liver disease: a systematic review. JAMA 313:2263-73. doi: 10.1001/jama.2015.5370

4. Meydan, C., Shenhar-Tsarfaty, S., and Soreq, H. 2016. MicroRNA regulators of anxiety and metabolic disorders. Trends Mol. Med. 22:798-812. doi: 10.1016/j. molmed.2016.07.001

5. Beddall, B. G. 1968. Wallace, Darwin, and the theory of natural selection. J. Hist. Biol. 1:261-323.

6. Soreq, H. 2015. Checks and balances on cholinergic signaling in brain and body function. Trends Neurosci. 38:448-58. doi: 10.1016/j.tins.2015.05.007

7. Soreq, H. 2014. Dimmer (Hebrew). Odyssey 25:20-5.

8. Martin, S., and Parton, R. G. 2006. Lipid droplets: a unified view of a dynamic organelle. Nat. Rev. Mol. Cell Biol. 7:373-8. doi: 10.1038/nrm1912

9. Hanin, G., Yayon, N., Tzur, Y., Haviv, R., Bennett, E. R., Udi, S., et al. 2018. miRNA-132 induces hepatic steatosis and hyperlipidaemia by synergistic multitarget suppression. Gut 67:1124-34. doi: 10.1136/gutjnl-2016-312869

SUBMITTED: 23 July 2018; ACCEPTED: 19 December 2018;

PUBLISHED ONLINE: 14 January 2019.

EDITED BY: Pasquale Maffia, University of Glasgow, United Kingdom

CITATION: Soreq H (2019) Fear, Fat, and Genes: New Answers to Old Questions. Front. Young Minds 6:76. doi: 10.3389/frym.2018.00076

CONFLICT OF INTEREST STATEMENT: The author declares that the research was conducted in the absence of any commercial or financial relationships that could be construed as a potential conflict of interest.

COPYRIGHT (c) 2019 Soreq. This is an open-access article distributed under the terms of the Creative Commons Attribution License (CC BY). The use, distribution or reproduction in other forums is permitted, provided the original author(s) and the copyright owner(s) are credited and that the original publication in this journal is cited, in accordance with accepted academic practice. No use, distribution or reproduction is permitted which does not comply with these terms. 

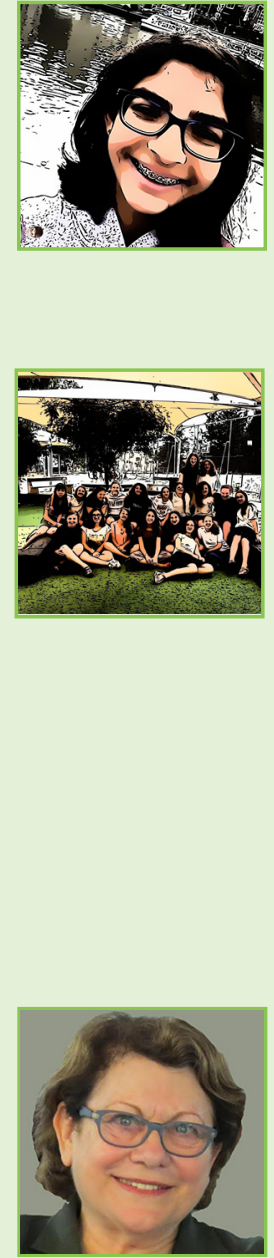

\section{YOUNG REVIEWERS}

\section{ANISHA, AGE: 14}

I am interested in the fields of science and math, and so when I grow up, I wish to be a biomedical engineer. In school, my favorite subjects are math and all the sciences. In my freetime, I enjoy playing the piano as well as reading. Some of my favorite books include The Wonderful Wizard of Oz and the Harry Potter series. I also enjoy trying new experiences and foods.

\section{ETGAR CLASS, OHR TORAH STONE SEMINARY, AGES: 13-14}

Ohr Torah Stone seminary is a religious high school for girls (grades 7-12) in Ramot neighborhood in Jerusalem. The seminary directs the students to spiritual and religious development and to excel in their studies and in social activities. In the eighth grade, the highest group in science studies is the Etgar ("Challenge") class of 25 students. The girls come from Jerusalem and its surroundings, and they are active in the various youth movements: Ezra, Bnei Akiva, and the religious scouts. In the field of science studies, the girls study various subjects in the sciences in depth and beyond the general curriculum, with the aim of continuing to study physics and biology.

\section{AUTHOR}

\section{HERMONA SOREQ}

I was attracted to Science as a high-school summer student at The Hebrew University. I was trained at The Hebrew University, Tel Aviv University, Weizmann Institute, and the Rockefeller University, and joined The Hebrew University in 1986, where I studied the genomic controllers of acetylcholine functioning in the healthy and diseased brain. Focusing on microRNAs (miRs), Soreq found that miRs compete with each other on suppressing anxiety and metabolic reactions. *hermona.soreq@mail.huji.ac.il 